\title{
Práticas corporais na extensão universitária na perspectiva da Educação em Saúde
}

\author{
Body practices in university extension from the perspective of Health Education
}

\author{
Gabriel de Aguiar Antunes ${ }^{1}$ \\ Priscila Rodrigues $\mathrm{Gil}^{2}$ \\ Giovana Zarpellon $\mathrm{Mazo}^{3}$
}

\section{RESUMO}

Este texto relata a proposta de extensão do projeto Envelhecimento Saudável, do curso de Educação Física da Universidade do Vale do Itajaí (Univali), projeto destinado a pessoas idosas participantes de um grupo de práticas corporais em uma Unidade Básica de Saúde (UBS). O objetivo é compreender a diversidade de práticas corporais para a Educação em Saúde. Trata-se de uma pesquisa de abordagem qualitativa que expressa os principais significados registrados nas intervenções do referido projeto. Apresenta-se uma proposta contrária ao olhar clínico/medicinal em detrimento de uma baseada em um real processo de educação amparado nas práticas corporais. Foi oportunizado aos idosos o protagonismo no agir e abrir possibilidades para transformação dos estilos de vida, pautado nas práticas corporais para a saúde.

Palavras-chave: Idoso. Saúde. Educação Física. Educação.

\begin{abstract}
This text reports the proposed extension project for Healthy Aging by the Physical Education course at the University of Vale do Itajaí (Univali), the project was aimed at elderly people participating in a group of bodily practices in a Basic Health Unit (UBS). The objective is: to understand the diversity of bodily practices for Health Education. This is a research with a qualitative approach that expresses the main meanings registered in the interventions of the referred project. A proposal contrary to the clinical/medical perspective is presented, which instead is based on a real education process focused on bodily practices. The elderly received the opportunity to take a leading role in acting and opening up possibilities for transforming their lifestyles, based on bodily practices for health.
\end{abstract}

Keyworks: Elderly. Health. Physical Education. Education.

\footnotetext{
${ }^{1}$ Doutorando em Ciências da Saúde e do Esporte na Universidade do Estado de Santa Catarina, Brasil; professor da Universidade do Vale do Itajaí, Santa Catarina, Brasil; membro do Grupo de Pesquisa Educação e Trabalho (Univali) (gabrieledfisicaantunes@gmail.com).

2 Mestranda em Ciências do Movimento Humano na Universidade do Estado de Santa Catarina, Brasil; professora na Rede Municipal de Educação de Florianópolis, Santa Catarina, Brasil (pri.gil@ hotmail.com).

${ }^{3}$ Doutora em Ciências do Desporto pela Universidade do Porto, Portugal; professora titular da Universidade do Estado de Santa Catarina, Brasil; coordenadora do Laboratório de Gerontologia (LAGER/UDESC); líder do Grupo de Pesquisa Atividade Física, Saúde e Envelhecimento (UDESC/CNPq) (giovana.mazo@udesc.br).
} 


\section{INTRODUÇÃO}

Concepções multidimensionais de Educação em Saúde deverão ser ampliadas. Sobretudo, atender às necessidades exclusivas de uma clientela de pessoas mais velhas é considerado um desafio de saúde pública mundial. Muitos desses sujeitos vivenciarão a vida com doenças crônicas, sedentários e muitas vezes acompanhados por invalidez (KIM et al., 2017).

Nesse sentido, há uma projeção reflexiva de estudiosos do campo da gerontologia apontando que as próximas gerações viverão mais anos, no entanto, com mais incapacidades relacionadas à saúde. Diante desse contexto, mudanças sociais, ciência e sociedade terão que refletir sobre políticas públicas de saúde, especialmente no contexto de países subdesenvolvidos e em desenvolvimento (ILCB, 2015).

As pesquisas com variáveis subjetivas, tal como Educação em Saúde, são capazes de originar predições comparáveis ou mais robustas com desfechos em saúde. Nesse sentido, esta pesquisa possibilita uma ampliação reflexiva com relação a estudos que envolvem o ensino, a pesquisa e a extensão atrelados à saúde de idosos.

A Universidade do Vale do Itajaí (Univali), por meio do projeto de extensão "Envelhecimento Saudável”, do curso de Educação Física, articula a formação acadêmica e profissional à inserção de práticas corporais para idosos da comunidade. São ações que intensificam o agir no cuidado, fundamentais nas conquistas da longevidade, estilo de vida saudável e qualidade de vida.

Muitas propostas de ações voltadas aos idosos estão articuladas, historicamente, por diferentes organizações comunitárias e governamentais, por políticas públicas vinculadas à educação e à saúde. No Brasil, a primeira instituição a propor um trabalho com idosos foi o Serviço Social do Comércio (SESC), de São Paulo, em 1963. Entretanto, com os idosos de 1977 é que realmente houve um trabalho com práticas corporais voltadas a essas pessoas e que se desenvolveu por todos os SESC do país (MAZO, 2008).

Paralelamente, as Universidades no Brasil iniciaram trabalhos de extensão voltados ao público idoso, tal como a Universidade Federal de Santa Catarina (UFSC) com o Núcleo de Estudos da Terceira Idade (NETI), e a Universidade do Estado de Santa Catarina (UDESC) com o Grupo de Estudos da Terceira Idade (GETI).

Contudo, sugere-se que essas propostas sejam cada vez mais articuladas a intervenções de Educação para a Saúde relacionadas, sobretudo, a uma valorização histórica e cultural da vida dos grupos de idosos de suas comunidades. É preciso haver uma conexão 
direta com as experiências de vida desses idosos e de suas diversidades étnicas, estéticas, biológicas, sociais e culturais, a fim de prover um atendimento em programas relacionados à saúde de um modo bem-sucedido e amplo que valorizem as práticas corporais da cultura local das diferentes comunidades.

As práticas corporais são fenômenos que se mostram, prioritariamente, ao nível corporal, constituindo-se em manifestações culturais, tais como os jogos, as danças, as ginásticas, os esportes, as artes marciais (CASTELLANI FILHO et al., 2009), entre outras. Essas possibilidades de manifestações envolvem diferentes linguagens corporais que se distanciam da racionalidade instrumental e favorecem experiências criativas e expressivas típicas de algumas regiões do Brasil e que podem atrair e sensibilizar os idosos a se tornarem fisicamente ativos.

Os esforços governamentais nas últimas décadas, no Brasil, foram ampliados. Em 2008, o Ministério da Saúde criou o Núcleo de Apoio à Saúde da Família (NASF), como o objetivo de apoiar a consolidação da Atenção Básica, ampliando as ofertas de saúde na rede de serviços, assim como a resolutividade, a abrangência e o alvo das ações, por meio de uma atuação integrada e multiprofissional, principalmente com a inserção do profissional de Educação Física.

Dessa forma, o objetivo deste artigo é compreender a diversidade de práticas corporais para a Educação em Saúde com idosos atendidos em uma Unidade Básica de Saúde (UBS) em um programa de extensão universitária da Univali, Campus Biguaçu. Assim, relata experiências de acadêmicos de Educação Física com idosos/as no projeto de extensão "Envelhecimento Saudável", que ocorre em uma UBS do município de Biguaçu-SC.

Trata-se de uma ação de extensão do curso de Educação Física da Univali, juntamente com profissionais do Núcleo de Apoio à Saúde da Família (NASF). Os acadêmicos do curso de Educação Física encontram oportunidades de capacitação no trabalho com a pessoa idosa, impactando qualitativamente na formação dos estudantes e na vida dos idosos no âmbito da saúde pública.

\section{PERCURSO METODOLÓGICO}

Trata-se de uma pesquisa de abordagem qualitativa (TURATO, 2005), em que são valorizadas a busca do significado das coisas e a vivência dos idosos, que expressa os principais resultados registrados nas intervenções do projeto de extensão Envelhecimento 
Saudável, da Univali, do curso de licenciatura em Educação Física - projeto de extensão mantido com recursos da própria instituição.

As ações foram desenvolvidas em uma UBS do município de Biguaçu-SC e foram oportunizadas a um público de 25 idosos/as, sendo três homens e 24 mulheres, com média de idade de 68,5 anos. As atividades foram propostas pelos acadêmicos extensionistas do curso de Educação Física. As intervenções foram realizadas três vezes na semana, com duração de uma hora, por meio de práticas corporais, como: danças, jogos, ginásticas, palestras, saídas a campo e apresentações artístico culturais.

\section{RESULTADOS E DISCUSSÃO}

\section{A diversidade de práticas corporais e os processos de Educação em Saúde ao idoso}

De certa maneira, a pessoa idosa percorreu uma extensa trajetória de relações históricas e sociais que impactaram de algum modo no seu estilo e qualidade de vida, e apresentam percepções diversificadas em torno da saúde em virtude de demonstrarem diferentes condições de saúde. Alguns precisam de muita atenção pelas fragilidades presentes no corpo como um todo.

Para Sousa (2012), podemos padecer por desequilíbrios do funcionamento normal dos órgãos do nosso corpo, mas também pela consciência própria, em nossa percepção, por educação, valores sociais, culturais e morais que condicionam e dão sentido aos nossos modos de viver. Nesse processo, a saúde e a doença ganham uma grande dimensão na condição humana e ultrapassam os fatores biológicos.

Ao longo das vivências e experiências no projeto de extensão "Envelhecimento Saudável" foi possível identificar que os/as idosos/as se sentiam excluídos/as pela sociedade, com poucas oportunidades de inserção e estigmas de inutilidade. Afinal de contas, o envelhecimento populacional não é homogêneo para as pessoas, sofre influência dos processos de discriminação e exclusão associados ao gênero, à etnia, ao racismo, às condições sociais e econômicas, à região geográfica de origem e à localização de moradia (BRASIL, 2006).

Diante desse contexto, o papel de agentes na conquista de direitos dos/as idosos/as identificou que as intervenções do projeto posto subsidiaram relações com as práticas corporais refletidas em questões sociais, culturais e do próprio contexto de diversidade da condição deles/as nas comunidades. Nas intervenções, buscou-se desmistificar o 
movimento/exercício físico como um remédio e contextualizá-lo como uma expressão de movimento refletida por ações corporais, movimentos e gestos em um contexto de linguagens que tematizassem as práticas oriundas historicamente da cultura corporal do grupo de idosos/as. Colaborou-se com as ações:

prevenir, compreender, promover, proteger e recuperar a saúde, mediante programas e medidas educativas e de lazer que possivelmente colaboraram com a sensibilização do grupo a um estilo de vida e qualidade de vida mais saudáveis. Ressalta-se que esse tipo de intervenção é recomendada pelas diretrizes da Política Nacional do Idoso, e que contribui com formas alternativas de realização, ocupação e educação da pessoa idosa, proporcionando sua integração às demais gerações. (BRASIL, 1994, p. 2).

Nas trocas interativas, os idosos tiveram a oportunidade de ressignificar a ocorrência social das brincadeiras, danças, lutas, esportes e ginásticas, reconhecendo suas múltiplas significações e promovendo uma diversidade de comportamentos que poderiam torná-los mais ativos. Nessa perspectiva, as propostas de práticas corporais não se deram pelo olhar clínico/medicinal, mas com um real processo de educação, envolvidas em diferentes práticas corporais, como linguagem, na companhia dos amigos e pela possibilidade de lazer, e do poder movimentar-se.

Em torno de pesquisas relacionadas à saúde do idoso com profissionais de Educação Física, o apoio social na literatura atual é encarado como uma estratégia de mediação para motivação e aderência dos idosos aos programas de Educação em Saúde. A socialização é um dos fatores responsáveis por ganhos de saúde e qualidade de vida (BENEDETTI; RIBEIRO; KONRAD, 2019). Nesse sentido, foi possível identificar que a vivência solitária dos/as idosos/as era desmotivadora para as práticas corporais e que eles/elas, ao estabelecerem parcerias com amigos/as no grupo da UBS, passaram a ser mais ativos/as fisicamente. Principalmente nas atividades físicas coletivas, bem como ir e voltar para o projeto caminhando em companhia de amigos/as. Para Nahas (2010), ser ativo fisicamente envolve o contato de pessoas e diferentes oportunidades inclusivas com estímulos comunicativos que ampliam as redes de relações sociais.

Os processos preventivos demandam ações integradas ao cotidiano dos/as idosos/as, em seu viver. Mazo (2008) esclarece que o termo "ativo" se refere à continuidade da participação na vida social, cultural, espiritual, cívica e não apenas fisicamente ativo. Não devemos descartar a importância do aspecto físico na qualidade de vida dos/as idosos/as, mas também é preciso valorizar e incluir os demais aspectos. 
Nas práticas, foram oportunizadas ações expressivas e de interação na diversidade de movimento e diálogo, desde os alongamentos em grupos, que tiveram o objetivo de ampliar a consciência corporal e interagir com o próximo, e instigar o grupo a sentir e pensar novas maneiras de manter o corpo com mobilidade e a percepção dos limites corporais. Para tanto, utilizou-se de recursos como balões, bolas, aparelhos de ginástica, objetos da natureza e yoga no Campus da Univali. Desafios corporais com percepções de habilidades de movimento envolvendo amplamente o corpo, por exemplo, com os balões e as bolas, envolveram manobras desde a ponta dos pés, os braços e as mãos, até a cabeça. Movimentos que possibilitam autonomia, criatividade e muita imaginação e que despertaram alegria e prazer e ressignificaram o movimento. Assim como no estudo de Santos et al. (2020), no qual as atividades recreativas proporcionaram a sensação de prazer e alegria entre os/as idosos/as que participaram da pesquisa.

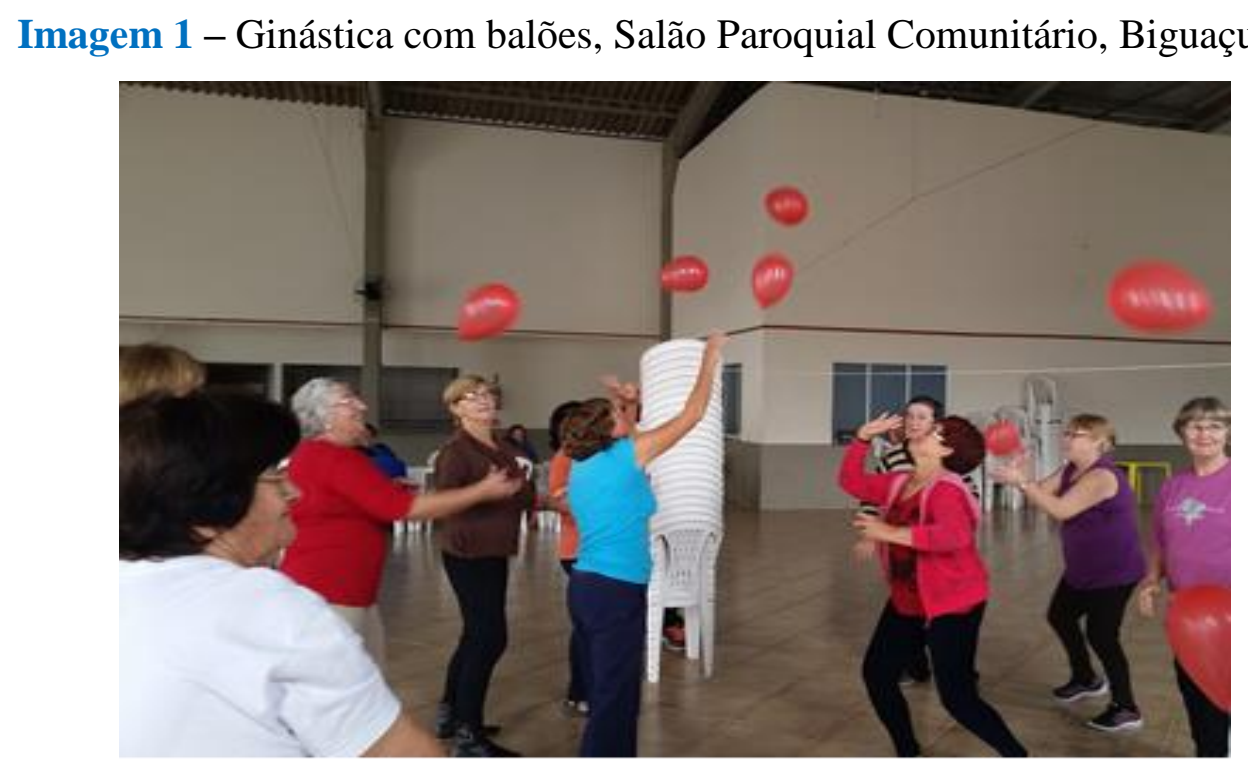

Fonte: Arquivo dos pesquisadores (2021).

Entre as diversas práticas, as caminhadas ao ar livre e de observação do meio ambiente foram muito interessantes, pois favoreceram o olhar contemplativo e o desejo de movimento em contato com a natureza. Proporcionar a interação com a natureza favoreceu a promoção da saúde como um todo. No caso dos/as idosos/as, os/as motiva a aderir a programas de atividade física (MAZO, 2008). Ao longo das intervenções foi possível perceber como os diálogos foram motivados em virtude das experiências das caminhadas, de uma prática que se tornou mais agradável e contemplativa. 
Foram instigados os propósitos do lazer e os/as idosos/as tiveram autonomia para as escolhas das práticas, favorecendo a diversão e a adesão às atividades durante todo o programa desenvolvido. Para Kunz (2010), o "se movimentar" como diálogo homem-mundo necessita ser ampliado como acontecimento relacional. Nessa perspectiva, procurou-se inovar nas práticas corporais, pois quando ocorre o movimento, mesmo com limitações, a pessoa experiencia sua corporeidade, e nela vive sensações e pensamentos ao empregar diversos sentidos. Os gestos estão sempre localizados no espaço comunicativo com o mundo, por isso, o fluxo de movimentos acontece em um horizonte de comunicação, ou zona de corporeidade. Isso ocorre desde o simples uso das roupas, que se tornam anexos do corpo, até as ações habituais que incorporam os instrumentos utilizados (KUNZ, 2001).

Na corporeidade ocorre religações na sua constituição, do corpo como integrado em diferentes partes e funções. O corpo é indivisível, não está isolado da existência e estabelece relações sociais; é corpo-social que, na dinâmica do corpo em movimento, busca ampliar a atenção para sentir e entender suas condições, limitações e possibilidades. Cada um pode verificar a sua trajetória e condição real física, biológica, psicológica, social e cultural e os seus impactos na saúde (ALMEIDA; BASTOS, 2017).

Nos encaminhamentos de práticas corporais, envolvendo as estruturas comunitárias e acessíveis, foram desenvolvidas aulas nas academias da saúde, ao ar livre, na praça próxima da UBS. Nas intervenções propostas nessas academias, os/as idosos/as reconheceram os benefícios de se manter em movimento. A utilização dos aparelhos oportunizou aulas conceituais a fim de empoderar a autonomia para os exercícios físicos. Foi identificado nas falas deles/delas que o livre acesso, sem orientação profissional, pode demandar riscos em relação às lesões, quedas, sobrecargas ou ineficiência do exercício.

As dinâmicas criativas nas práticas corporais necessitam estar atreladas ao prazer pelo movimento espontâneo, comunicativo e com significados intersubjetivos articulados com as experiências. Nesse sentido, as diferentes práticas corporais foram realizadas conforme a aceitação do grupo, sendo possível perceber as preferências e desejos, os quais foram considerados nas propostas de intervenção. Com isso, os/as idosos/as tiveram a oportunidade de conversar de forma a ampliar as possibilidades de comunicação entre si e entre os acadêmicos da Educação Física. Geralmente, a maioria chegava a UBS reclamando de sua capacidade física, de algo familiar ou qualquer outra situação, de forma que muitas palavras e ações foram necessárias para animá-los e motivá-los para as atividades. 
Imagem 2 - Práticas de yoga na Univali, Campus Biguaçu

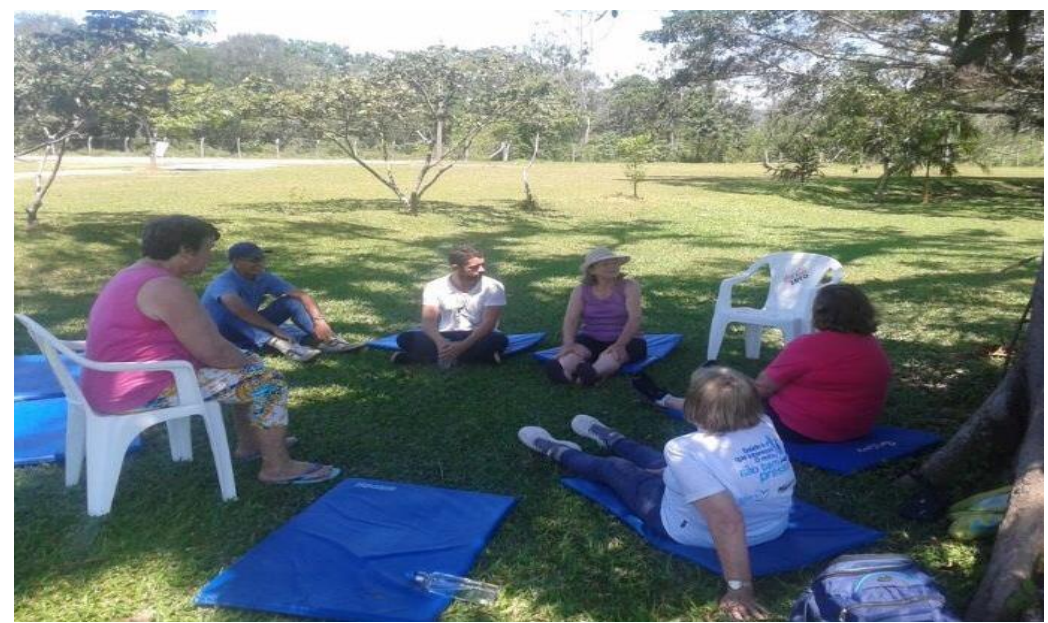

Fonte: Arquivo dos pesquisadores (2021).

As visitas com o grupo à Univali foram ações educativas e inclusivas, muito importantes a fim de ampliar o acesso e o contato com o meio acadêmico. Do grupo, originaram-se percepções diferentes sobre a instituição. Os/as idosos/as perceberam-na como parte do bairro, como a que oferece serviços, os quais também podem beneficiar a eles/elas. Uma instituição que emprega sua função extensionista e de construção do conhecimento tornou-se parte da vida dos/as idosos/as, com seus recursos e instalações. Nas visitas, os/as participantes do projeto vivenciaram os ambientes da universidade, como biblioteca, espaços de convivência dos universitários, laboratório de anatomia, quadra poliesportiva, bosque, cantina, salas de informática, ambientes esportivos e de práticas corporais.

Imagem 3 - Práticas de jogos de memorização na biblioteca da Univali, Campus Biguaçu

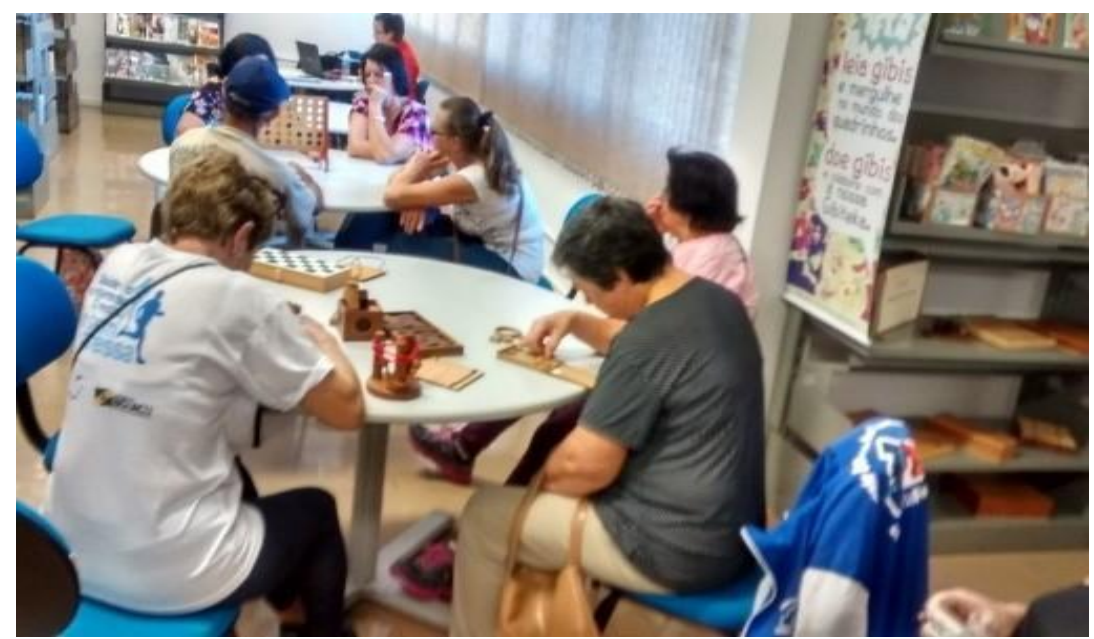

Fonte: Arquivo dos pesquisadores (2021). 
Em muitos ambientes da universidade foram realizadas vivências práticas. Na sala de informática, ocorreram atividades de inclusão digital a fim de realizarem pesquisas e jogos nos computadores. Na sala de práticas corporais, foram realizadas aulas de ginástica e yoga com materiais alternativos e aparelhos de ginástica artística e rítmica.

Imagem 4 - Aulas de informática no Laboratório de Tecnologia da

Univali, Campus Biguaçu

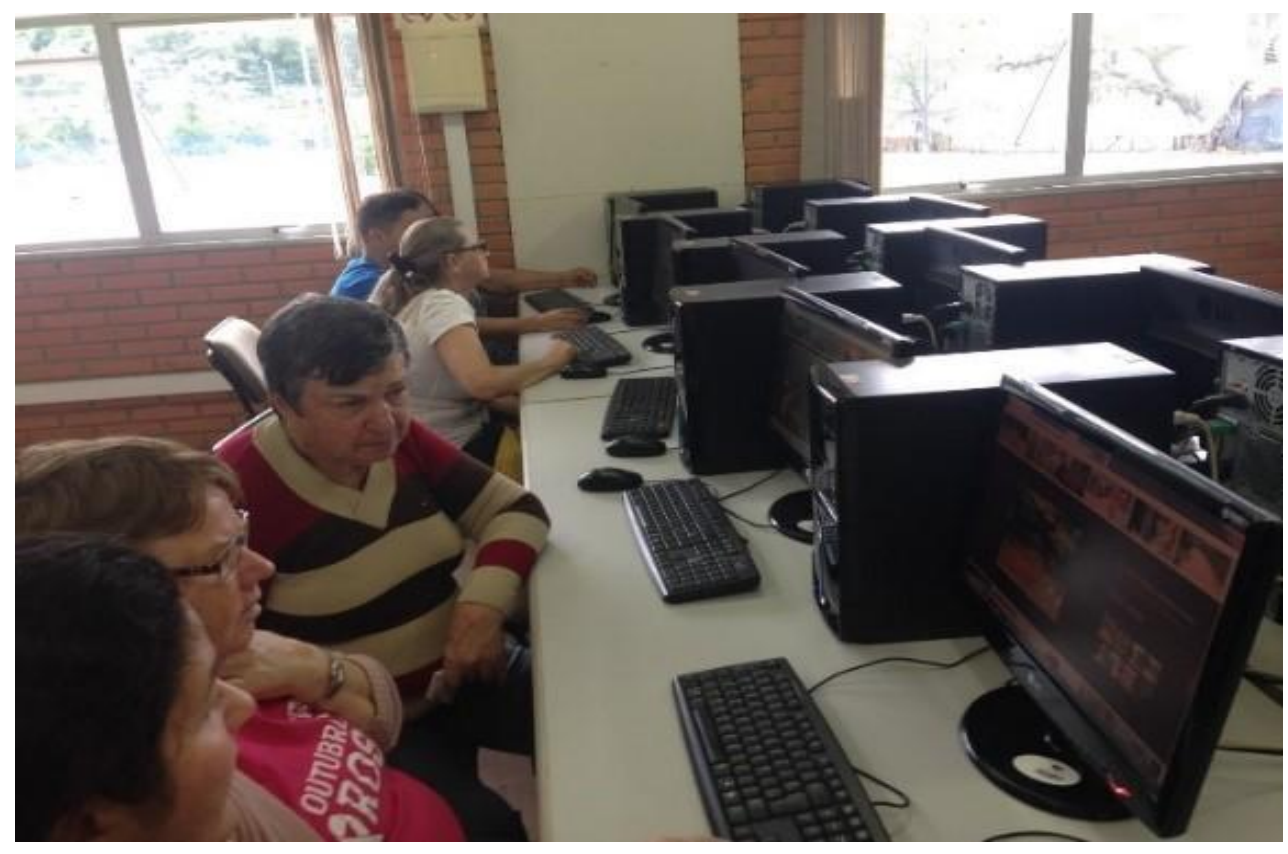

Fonte: Arquivo dos pesquisadores (2021).

As propostas do projeto "Envelhecimento Saudável” alcançaram uma interlocução intergeracional, pois os/as idosos/as puderam conviver com os/as universitários/as. Ressaltase que o Estatuto do Idoso, no cap. V art. 20, define que o idoso tem direito à educação, à cultura, ao esporte, ao lazer, às diversões, aos espetáculos, a produtos e serviços que respeitem sua peculiar condição de idade (BRASIL, 2013). Refletindo sobre esses marcos legais, buscou-se garantir o acesso e a ampliação das práticas educativas.

$\mathrm{Na}$ quadra da Univali oram oferecidas diversas práticas de danças e ensaios para participação do grupo em eventos de ginástica e dança. Para Mazo, Lopes e Benedetti (2001), a dança possibilita diversos benefícios para os/as idosos/as, que vão do conhecimento do seu próprio corpo, resgate cultural, aumento da capacidade de expressão, comunicação, até aceitação individual e de grupo. Trata-se de uma atividade prazerosa e que pode transformar sensações e pensamentos em movimentos que se comunicam. Nesse processo, percebeu-se a 
importância de eventos de lazer para oportunizar a esse grupo apresentações artísticas em eventos culturais. Na produção da coreografia para apresentação, os/as idosos/as foram protagonistas do processo de construção coreográfica. Foram eles/elas que escolheram as músicas e deram sugestões aos movimentos.

Imagem 5 - Apresentação do projeto "Envelhecimento Saudável" em festival de danças para idosos da Universidade do Estado de Santa Catarina-UDESC

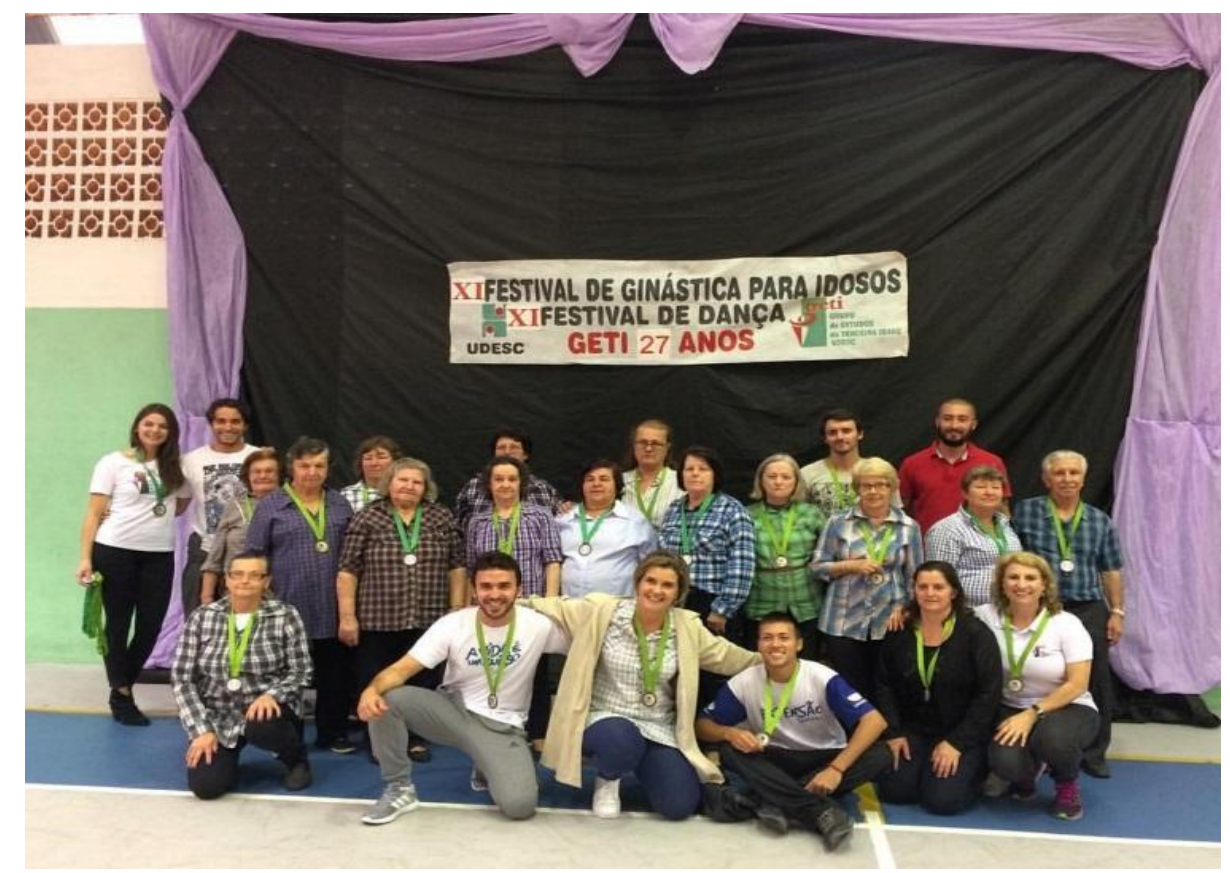

Fonte: Arquivo dos pesquisadores (2021).

Segundo Mazo (2008), a sociedade tende a ver o envelhecimento como um tempo de declínio. Os/as idosos/as muitas vezes podem acreditar que é tarde para melhorar sua saúde e sua função física e mental. Os diálogos buscaram ressignificar os pensamentos de incapacidade, gerando autoconfiança, autonomia e autoestima. Uma proposta prática, muito criativa e que favoreceu a ampla movimentação, foi a ginástica geral. $O$ aparelho "paraquedas", incluído para a construção coreográfica, foi muito importante nas dinâmicas de movimentos e envolveu dança e ritmos populares brasileiros. 
Imagem 6 - Práticas corporais de ginástica geral com o aparelho "paraquedas" na Academia da Saúde - praça próxima à UBS

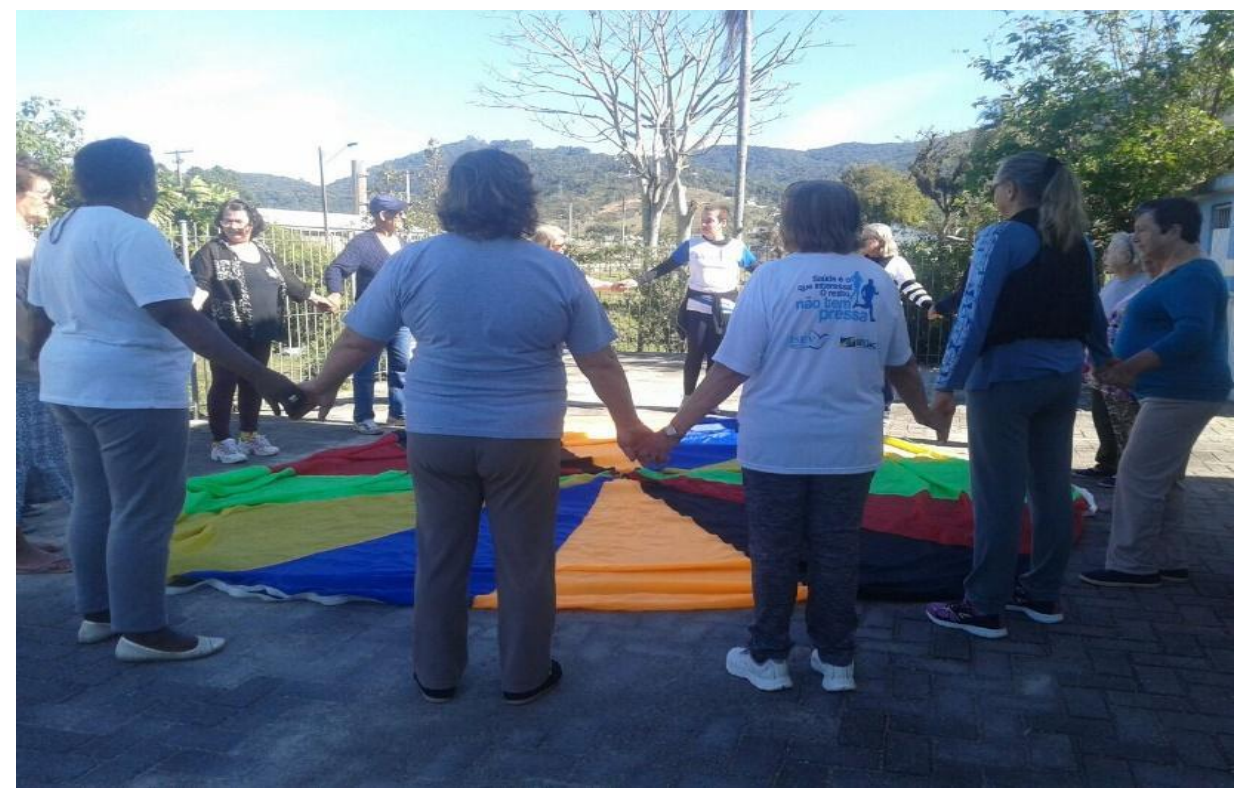

Fonte: Arquivo dos pesquisadores (2021).

As práticas envolvendo a ginástica foram muito construtivas na interação e cooperação, com desafios rítmicos. $\mathrm{O}$ aparelho alternativo para a criação coreográfica exigiu atenção e envolvimento nas dramatizações de acordo com o tema escolhido. Todos/as fizeram parte da construção coreográfica com sugestões criativas, possibilitando ação expressiva e prazerosa.

O envolvimento artístico, cultural e social foi valioso para pensar a saúde com perspectiva ampliada. A ginástica e a dança foram práticas corporais que estimularam o corpo em sua totalidade. Os diferentes ritmos vivenciados envolvem sentir, coordenar o corpo e a musicalidade. A atenção foi fator essencial nas dinâmicas, possibilitando o pensar e o agir criativo. A apresentação coreográfica que os/as idosos/as realizaram em um evento de dança foi a conquista da superação e do ser artístico. A satisfação pessoal e coletiva favoreceu o bem-estar, fortalecida pelas oportunidades de interação social e cultural.

O esporte também foi uma prática favorável para o bem-estar, que promoveu capacidades físicas de resistência e mobilidade, além das lembranças dos jogos da infância e suas evoluções. O badminton foi uma prática corporal que envolveu ressignificações culturais e sociais, que desafiou a construção das petecas com habilidades artísticas e revelou memórias das brincadeiras. Foram registros que promoveram prazer e desejo de realizar as habilidades ainda registradas nas memórias do grupo. 
Imagem 7 - Práticas corporais de esportes com o badminton na

Academia da Saúde, praça próxima à UBS

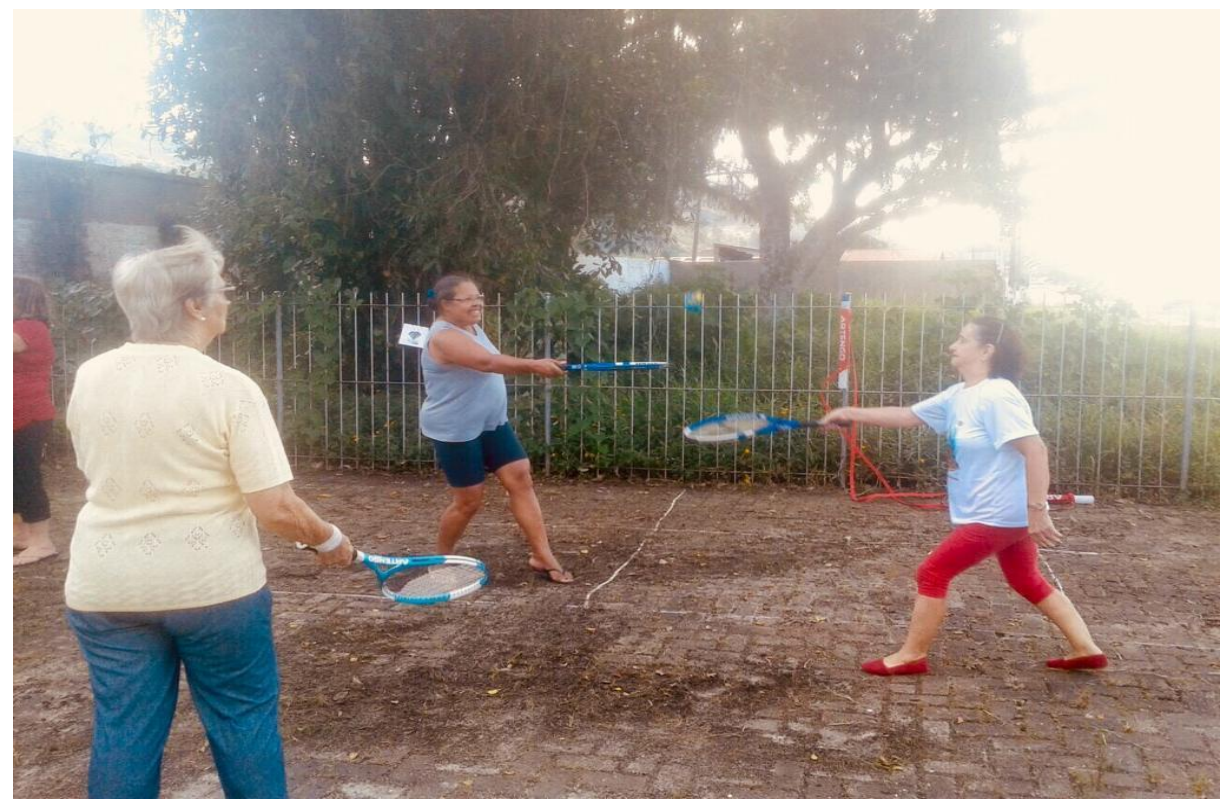

Fonte: arquivo dos pesquisadores.

Foi possível refletir sobre as vivências do grupo com esse esporte e possibilitou a eles/as conhecerem uma nova prática corporal acessível, ampliando e valorizando a expressividade de cada um no jogo. As práticas proporcionaram revisar os aspectos históricos, materiais utilizados, curiosidades e a experimentação na vivência dos idosos/as, além do prazer de estar no grupo.

Muitos desafios para a garantia do direito à saúde dos/as idosos/as serão travados e a Educação Física é uma das áreas da saúde que poderá garantir com sucesso a inserção deles/as em programas que valorizem a possibilidade de incrementos em um estilo de vida saudável. Nesse sentido, as universidades são coadjuvantes na realização de práticas de ensino, pesquisa e extensão que ampliam o acesso desse grupo, a partir de políticas públicas de Atenção Básica, tão necessárias na perspectiva integradora do ser humano e da saúde do idoso na sociedade.

\section{CONSIDERAÇÕES FINAIS}

As diversas práticas corporais envolvendo arte, cultura e lazer no contexto da extensão universitária favoreceram a ampliação da visão de mundo dos/as idosos/as participantes do projeto de extensão e contribuíram para assumirem diferentes papéis sociais. Possibilitaram reflexões pessoais deles/delas, imersos/as em sua própria realidade, sobre questões 
relacionadas à saúde, e favoreceram a manutenção da funcionalidade, independência e autonomia. Os profissionais da UBS puderam ampliar as experiências de vida dos/as idosos/as, por meio da extensão universitária. A proposta possibilitou olhar novas perspectivas de atuação profissional aos/às acadêmicos/as de Educação Física, sensibilizandoos/as para condições de trabalhos reais no contexto da saúde.

Foram observadas ações em que o grupo de idosos/as obteve mais autonomia, além da melhora da capacidade de organização, de expressão e decisão nos jogos. O encorajamento para a criação e apresentação artística foi resultante de um processo de motivação, assumindo novos papéis. A ginástica geral foi expressão artística permeada por muita mobilidade, criatividade, ludicidade e desafios de superação nos arranjos das coreografias. Oportunizaram-se caminhos para reflexões sobre as práticas corporais, novas formas de linguagens e ampliação das habilidades comunicativas. Foi assegurado a esse público o protagonismo no agir ao abrir possibilidades para transformação dos estilos de vida, envolvidas nas ações educativas, pautadas nas práticas corporais para a saúde.

\section{REFERÊNCIAS}

ALMEIDA, L.; BASTOS, P. R. H. O. O desvelar do significado do corpo envelhecido para o idoso: uma compreensão fenomenológica. Revista Espacios, Caracas, v. 38, n. 29, 2017. Disponível em: https://www.revistaespacios.com/a17v38n29/17382923.html. Acesso em: 15 set. 2021.

BENEDETTI, T. R. B.; RIBEIRO, C. G.; KONRAD, L. VAMOS identificar o apoio social? Moodle Grupos. Florianópolis: UFSC, 2019. Disponível em:

Moodle: https://grupos.moodle.ufsc.br/course/view.php?id=748\#section-10. Acesso em: 18 ago. 2021.

BRASIL. Lei $\mathbf{n}^{\mathbf{0}}$ 8.842, de 4 de janeiro de 1994. Dispõe sobre a Política Nacional do Idoso, cria o Conselho Nacional do Idoso e dá outras providências. Brasília, DF, 1994. Disponível em: http://www.planalto.gov.br/ccivil_03/leis/18842.htm. Acesso em:

BRASIL. Lei $\mathbf{n}^{0}$ 10.741, de 1 de outubro de 2003. Dispõe sobre o Estatuto do Idoso e dá outras providências. Brasília, DF, 2013. Disponível em:

http://www.planalto.gov.br/ccivil_03/LEIS/2003/L10.741compilado.htm. Acesso em:

BRASIL. Ministério da Saúde. Secretaria de Atenção à Saúde. Departamento de Atenção Básica. Envelhecimento e saúde da pessoa idosa. Brasília: Ministério da Saúde, 2006. (Cadernos de Atenção Básica; 19). Disponível em: https://bvsms.saude.gov.br/bvs/publicacoes/evelhecimento_saude_pessoa_idosa.pdf. Acesso em: 19 set. 2021. 
BRASIL. Ministério da Saúde. Secretaria-Executiva. Mais saúde: direito de todos: 20082011. 3. ed.. Brasília: Ministério da Saúde, 2010. (Série C. Projetos, Programas e Relatórios). Disponível em:

https://bvsms.saude.gov.br/bvs/publicacoes/mais_saude_direito_todos_3ed.pdf. Acesso em: 18 set. 2021.

CASTELLANI FILHO, L. et al. Metodologia do ensino de educação física. São Paulo: Cortez, 2009.

ILCB - INTERNATIONAL LONGEVITY CENTRE BRAZIL. Envelhecimento ativo: um marco político em resposta à Revolução da Longevidade. Rio de Janeiro: ILC-Brasil, 2015. Disponível em: https://ilcbrazil.org/portugues/wpcontent/uploads/sites/4/2015/12/Envelhecimento-Ativo-Um-Marco-Pol\%C3\%ADtico-ILCBrasil_web.pdf. Acesso em:

KIM, E. S. et al. Association between purpose in life and objective measures of physical function in older adults. JAMA Psychiatry, Londres, v. 74, n. 10, p. 1.039-1.045, 2017. Doi: 10.1001/jamapsychiatry.2017.214.

https://jamanetwork.com/journals/jamapsychiatry/fullarticle/2648692. Acesso em:

KUNZ, E. Educação física: ensino e mudanças. 2. ed. Ijuí: Unijuí, 2001.

KUNZ, E. Transformação didático-pedagógica do esporte. 6. ed. Ijuí: Unijuí, 2010.

MAZO, G. Z. Atividade física, qualidade de vida e envelhecimento. Porto Alegre: Editora Sulina, 2008.

MAZO, G. Z.; LOPES, M. A.; BENEDETTI, T. R. B. Atividade física e o idoso: concepção gerontológica. Porto Alegre: Sulina, 2001.

NAHAS, M. V. Atividade física, saúde e qualidade de vida: conceitos e sugestões para um estilo de vida ativo. 5. ed. Londrina: Midiograf, 2010.

SANTOS, M. F. et al. Atividade de promoção à saúde em um grupo de idosos. Em Extensão, Uberlândia, v. 19, n. 1, 2020. Doi: 10.14393/REE-v19n12020-50738. Disponível em: https://seer.ufu.br/index.php/revextensao/article/view/50738. Acesso em: 15 set. 2021.

SOUSA, A. B. R. Filosofia da saúde: fundamentação para uma práxis educativa. Rio de Janeiro: Interciência, 2012.

TURATO, E. R. Métodos qualitativos e quantitativos na área da saúde: definições, diferenças e seus objetos de pesquisa. Revista de Saúde Pública, São Paulo, v. 39, p. 507-514, 2005. Doi: 10.1590/S0034-89102005000300025. Disponível em: https://www.scielo.br/j/rsp/a/qtCBFFfZTRQVsCJtWhc7qnd/?lang=pt. Acesso em: 18 set. 2021.

Submetido em 29 de setembro de 2021. Aprovado em 8 de dezembro de 2021. 